\title{
Altered Gene Expression Profiles in Peripheral Blood Mononuclear Cells in Obese Subjects
}

\author{
Kyungho Jang a Tao Tong ${ }^{b}$ Jinhui Lee ${ }^{c}$ Taesun Park ${ }^{c}$ Howard Leed, e \\ ${ }^{a}$ Center for Clinical Pharmacology, Biomedical Research Institute, Jeonbuk National \\ University Hospital, Jeonju, South Korea; ${ }^{b}$ Beijing Advanced Innovation Center for Food \\ Nutrition and Human Health, College of Food Science and Nutritional Engineering, China \\ Agricultural University, Beijing, China; ${ }^{c}$ Department of Food and Nutrition, Brain Korea 21 \\ PLUS Project, Yonsei University, Seoul, South Korea; ${ }^{d}$ Department of Clinical Pharmacology \\ and Therapeutics, Seoul National University College of Medicine and Hospital, Seoul, South

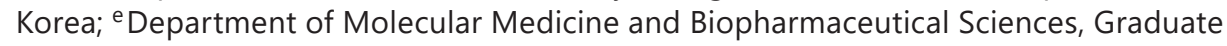 \\ School of Convergence Science and Technology, Seoul National University, Seoul, South \\ Korea
}

\section{Keywords}

PBMC $\cdot$ Gene expression · Obesity

\begin{abstract}
Introduction: Gene expression profiles in human peripheral blood mononuclear cells (PBMCs) may act as a useful tool to better understand obesity. We investigated gene expression levels in PMBCs for possible differences between obese and non-obese subjects (19-55 years) and evaluated correlations between gene expression in PBMCs and clinical obesity indices. Methods: Body weight, BMI, fat amount, fat percentage, waist/hip ratio, leptin, and adiponectin levels were determined in 30 obese and 20 non-obese subjects. Expression levels of 19 genes, which were differentially expressed by clinical obesity indices in the PBMCs of high fat-fed rats, were determined in their PBMCs using real-time PCR. Results: The expression of 9 of 19 previously selected genes was significantly correlated with one or more clinical obesity indices. Both TFEC and CCL2 expression were negatively correlated with BMI, fat amount, fat percentage, waist/hip ratio, and leptin concentration. Similarly, TNFAIP2, VCAN, ASSI, IRF1, and HK3 expression negatively correlated with some clinical obesity indices, such as TNFAIP2 for BMI, fat amount, fat percentage, and waist/hip ratio, VCAN for fat amount, fat percentage, and waist/hip ratio, ASS1 for BMI and fat amount, IRF1 for BMI, fat amount, and fat percentage, and HK3 for fat amount. In contrast, both TNF- $\alpha$ and LPL expression were positively cor-
\end{abstract}

K.J. and T.T contributed equally to the current work.

Howard Lee

Department of Clinical Pharmacology and Therapeutics Seoul National University College of Medicine and Hospita 103 Daehak-ro, Jongno-gu, Seoul 110799 (South Korea) howardlee@snu.ac.kr
Taesun Park

Department of Food and Nutrition

Yonsei University

50 Yonsei-ro, Seodaemun-gu, Seoul 120749 (South Korea)

tspark@yonsei.ac.kr 
Jang et al.: PBMCs as a Biomarker for Obesity

related with waist/hip ratio. Conclusion: We identified 9 of 19 genes in human PBMCs that significantly correlated with one or more clinical obesity indices. Because these genes have a mechanistic basis for the development or progression of obesity and its metabolic derangements, they may help to determine possible underlying mechanisms for obesity.

(C) 2020 The Author(s)

Published by S. Karger AG, Basel

\section{Introduction}

Overweight and obesity are abnormal and excessive fat accumulation, each of which is diagnosed when body mass index (BMI) is $\geq 25$ and $\geq 30 \mathrm{~kg} / \mathrm{m}^{2}$ for adults, respectively [1]. The World Health Organization (WHO) has lowered the cutoff BMI for obese Asians to $>27.5$ $\mathrm{kg} / \mathrm{m}^{2}$ [2]. Overweight and obesity are major risk factors for a number of chronic diseases such as diabetes, cardiovascular diseases, and cancer. Obesity is more troublesome in children than in adults because overweight and obese children are likely to stay obese during their entire lifetime, rendering them at a higher risk for various metabolic diseases even at young adulthood [3]. Therefore, early identification of individuals who are overweight, or likely to develop overt obesity at a later stage of life, is important.

A biomarker is an indicator that objectively measures and evaluates the normal or pathogenic biological process [4]. Biomarkers can be used to screen and diagnose a disease. Biomarkers are also helpful to evaluate the effect of a drug and to predict the prognosis of a disease. Because blood interacts with every tissue and organ in the body via the circulation, blood-derived biomarkers may reflect general health or the disease status. For example, hemoglobin $A_{1 c}$ in blood is a well-established biomarker or surrogate for diabetes that indicates the presence and severity of hyperglycemia. However, no novel blood-derived biomarker is currently available to diagnose subclinical obesity, to predict the prognosis of obesity, or to evaluate the effect of an anti-obesity treatment.

Recent studies showed that gene expression profiles assessed in peripheral blood mononuclear cells (PBMCs) may act as biomarkers for several diseases, such as Behçet's disease [5], Crohn's disease [6], and ulcerative colitis [6]. PBMCs are mainly composed of monocytes and lymphocytes, which undergo immunophenotypic changes in various diseases [7]. The usefulness of PBMCs as a source of early biomarkers for obesity was tested in a previous study, where altered expression of key energy homeostatic genes in PBMCs signaled metabolic imbalances that could lead to obesity [8]. However, there is still insufficient evidence demonstrating the utility of gene expression profiles in human PBMCs to detect subclinical obesity or overweight.

The objectives of the present study were to evaluate and compare several gene expression profiles in human PBMCs between obese and non-obese subjects, and to identify the correlations between PBMC-derived gene profiles and clinical obesity indices.

\section{Materials and Methods}

\section{Subjects and Clinical Study}

Males or females $19-55$ years of age with a BMI $<27 \mathrm{~kg} / \mathrm{m}^{2}$ (non-obese group) or $\geq 27$ $\mathrm{kg} / \mathrm{m}^{2}$ (obese group), who were generally healthy otherwise based on a detailed medical history, physical examination, and laboratory tests, were included in this study. Subjects were excluded if they had taken any prescription medication for weight loss within 4 weeks prior to the time of blood sampling for PBMCs or had a history of changes in body weight $>10 \%$ within 6 months. All subjects visited the Clinical Trials Center at the Seoul National University

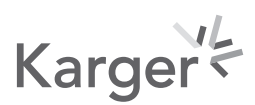


Jang et al.: PBMCs as a Biomarker for Obesity

Table 1. Primer sequences used for real-time PCR analyses

\begin{tabular}{lll}
\hline Gene description (symbol) & Forward primer (5'-3') & Reverse primer (5'-3') \\
\hline Chemokine (C-X-C motif) ligand 11 (CXCL10) & GGAATCTTTCTGCTTTGGGG & GGCAGTGGAAGTCCATGAAG \\
Ubiquitin D (UBD) & TGCAGGACCAGGTTCTTTTG & AGCTCCTCATCACGGGCTT \\
Immunoresponsive gene 1(IRG1) & CTGGCATTCATGGAATGAGG & TCCAGTTCGGAGCATGAAG \\
Hexokinase 3 (HK3) & GTGGACTTCCAGCAGAAGCA & AACCCTTGGTCCAGTTCAGG \\
Chemokine (C-X-C motif) ligand 11 (CXCL11) & GTCCATGGAATCCTGAACCC & GCAGCAAGTGTCCCAAAGAA \\
Argininosuccinate synthetase 1 (ASS1) & CTCCACGATGTCAATACGGC & CAACACCCCTGACATTCTCG \\
Serine (or cysteine) peptidase inhibitor, clade G, & & \\
$\quad$ member 1 (SERPING1) & TCTCCATGATGGCCTTGAAA & GAAGTACCCTGTGGCCCATT \\
Tumor necrosis factor- $\alpha$-induced protein 2 (TNFAIP2) & CCAGACAAGCCTAGGCAACA & GTCATGGCATCAAGGCTCAC \\
Transcription factor EC (TFEC) & AGAGAGCCCGAGAATTGGAA & AATCAACCGTGCCAAGTGAA \\
Interleukin $1 \beta$ (IL-1 3 ) & TGAAGCCCTTGCTGTAGTGG & ACAGGCTGCTCTGGGATTCT \\
Interferon regulatory factor 1 (IRF1) & GGTGATGTGGCATTTTCTGC & TACAAAAGCAGCCCGCTCTA \\
Signal transducer and activator of transcription 1 (STAT1) & ATTGCGAATGATGTCAGGGA & GCCATCACATTCACATGGGT \\
Versican (VCAN) & CAGTCCAACGGAAGTCATGC & CCCATCTCACAAGCATCCTG \\
Lipoprotein lipase (LPL) & TCAACATGCCCAACTGGTTT & AGTATGCAGAAGCCCCGAT \\
Toll-like receptor 2 (TLR2) & ATGTTCCTGCTGGGAGCTTT & ACTGGTGTCTGGCATGTGCT \\
Toll-like receptor 4 (TLR4) & AATGCCCACCTGGAAGACTC & CCACATGTCAGGCCTTATGC \\
Chemokine (C-C motif) ligand 2 (CCL2) & CTTCGGAGTTTGGGTTTGCT & GCCAAGGAGATCTGTGCTGA \\
Interleukin 6 (IL-6) & CAGCTCTGGCTTGTTCCTCA & TGGCTGAAAAAGATGGATGC \\
Tumor necrosis factor- $\alpha$ (TNF- $\alpha$ ) & CGGATCATGCTTTCAGTGCT & TGAAAACAACCCTCAGACGC \\
\hline & &
\end{tabular}

Hospital after a 12-h overnight fast and provided written informed consent and necessary information. Thereafter, their body weight, height, BMI, fat, fat percentage, and waist/hip ratio were determined using InBody $570^{\circledR}$ (InBody, USA). The subjects were divided into 2 groups according to their BMI. On the same day, blood samples were collected after a 12 -h overnight fast to determine the gene profiles in PBMCs, leptin, adiponectin, insulin, total cholesterol, triglycerides, and free fatty acids.

\section{PBMC Isolation}

PBMCs were isolated by passing blood samples through Ficoll-Paque (GE Healthcare) at $400 \mathrm{~g}$ for $30 \mathrm{~min}$. Following buffy coat removal from the plasma-Ficoll interface, cells were washed once in phosphate-buffered saline before being frozen for use at a later time.

\section{RNA Extraction and Real-Time PCR}

We previously identified 19 genes, which were differentially expressed by clinical obesity indices in the PBMCs of high fat-fed rats using the whole genome microarray analysis method [9]. Those PMBC genes included several genes with known biological functions related to obesity and metabolic syndrome, for example, C-X-C motif chemokine ligand 10 (CXCL10, +49.0-fold) [10], ubiquitin D (UBD, +9.9-fold) [11], immunoresponsive gene 1 (IRG1, +8.7fold) [12], hexokinase 3 (HK3, +8.3-fold) [13], C-X-C motif chemokine ligand 11 (CXCL11, +7.1-fold) [14], argininosuccinate synthetase 1 (ASS1, +6.2-fold) [15], serine (or cysteine) peptidase inhibitor, clade G, member 1 (SERPING1, +5.4 -fold) [16], tumor necrosis factor- $\alpha$ induced protein 2 (TNFAIP2, +4.9-fold) [17], transcription factor EC (TFEC, +4.6-fold) [18], interleukin $1 \beta$ (IL-1 $\beta,+4.5$-fold) [19], interferon regulatory factor 1 (IRF1, +4.4-fold) [20], signal transducer and activator of transcription 1 (STAT1, +3.0-fold) [21], versican (VCAN, +2.9-fold) [22], lipoprotein lipase (LPL, +2.9-fold) [23], toll-like receptor 2 (TLR2, +2.9-fold) [24], toll-like receptor 4 (TLR4, +2.9-fold) [24], C-C motif chemokine ligand 2 (CCL2, +2.7fold) [25], interleukin 6 (IL-6, +1.8-fold) [26], and tumor necrosis factor- $\alpha$ (TNF- $\alpha,+1.5$-fold) [26].

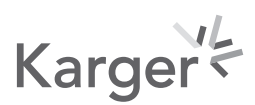


Jang et al.: PBMCs as a Biomarker for Obesity

Table 2. Baseline demographic and biochemical characteristics of obese $(n=30)$ and non-obese $(n=20)$ adults

\begin{tabular}{lccr}
\hline & $\begin{array}{c}\text { Obese }(n=30) \\
(\text { means } \pm \text { SD) }\end{array}$ & $\begin{array}{c}\text { Non-obese }(n=20) \\
\text { (means } \pm \text { SD) }\end{array}$ & $p$ value \\
\hline Age, years & $30.77 \pm 8.97$ & $31.10 \pm 9.49$ & 0.9003 \\
Females/males & $12 / 18$ & $0 / 20$ & $<0.0001$ \\
Weight, kg & $84.11 \pm 9.63$ & $67.74 \pm 10.15$ & 0.1802 \\
Height, cm & $169.57 \pm 8.39$ & $172.46 \pm 5.46$ & $<0.0001$ \\
BMI, kg/m & $29.36 \pm 2.30$ & $22.73 \pm 2.85$ & $<0.0001$ \\
Fat, kg & $30.14 \pm 5.89$ & $13.82 \pm 6.86$ & $<0.0001$ \\
Fat, \% & $35.93 \pm 7.02$ & $19.87 \pm 7.73$ & $<0.0001$ \\
Waist/hip ratio & $0.96 \pm 0.05$ & $0.84 \pm 0.05$ & 0.0001 \\
Leptin, pg/mL & $14,528.27 \pm 12,166.70$ & $1,985.20 \pm 1,858.01$ & 0.1582 \\
Adiponectin, ng/mL & $3,953.47 \pm 1,652.06$ & $6,512.60 \pm 3,496.73$ & 0.2473 \\
Insulin, mU/L & $14.69 \pm 7.25$ & $21.42 \pm 19.76$ & 0.5814 \\
Total cholesterol, mg/dL & $188.77 \pm 34.60$ & $178.50 \pm 22.41$ & 0.3671 \\
Triglycerides, mg/dL & $129.70 \pm 64.30$ & $119.65 \pm 60.20$ & $555.90 \pm 356.71$ \\
Free fatty acids, uEq/L & $478.00 \pm 156.64$ & 5 & \\
\hline
\end{tabular}

All subjects were in the fasting state prior to blood sampling and measurements of weight, height, BMI, fat amount, fat percentage, and waist/hip ratio. Student's $t$ test was applied.

Total RNA was extracted from PBMC using the TRIzol reagent (Life Technology, Carlsbad, CA, USA) according to the manufacturer's instructions. cDNA synthesis was performed with $1 \mu \mathrm{g}$ of total RNA, $5 \times$ RT buffer, $2.5 \mathrm{~mm}$ each dNTP, $0.1 \mathrm{M}$ dithiothreitol, $200 \mathrm{U} / \mu \mathrm{L}$ reverse transcriptase, and $40 \mathrm{U} / \mu \mathrm{L}$ RNase inhibitor at $37^{\circ} \mathrm{C}$ for $2 \mathrm{~h}$. Quantitative PCR was performed (after RNA reverse transcription) using iQ SYBR Green supermix (Bio-Rad, Hercules, CA, USA) with the CFX Connect ${ }^{\mathrm{TM}}$ real-time PCR detection system (Bio-Rad). All gene expression data were normalized to GAPDH. Primer sequences are listed in Table 1. The results on the optical density ratio of a target gene to GAPDH are presented as means \pm SEM of at least 3 different experiments.

\section{Statistical Analysis}

All data were expressed as means \pm SD. The differences in gene expression profiles and clinical variables between the obese and the non-obese group were analyzed using the twosample Student's $t$ test after log transformation when deemed appropriate. Spearman's correlation coefficient was also used to evaluate the association between the obesity parameters and gene expression profiles in PBMCs. A two-tailed $p<0.05$ was considered statistically significant.

\section{Results}

\section{Subjects}

A total of 30 obese (12 females and 18 males) and 20 non-obese subjects (no female and 20 males) were included in the study. Because the subjects were enrolled in the order of providing written informed consent, there were no female subjects in the non-obese group. Age, height, and baseline levels of insulin, total cholesterol, triglycerides, and free fatty acids did not differ between the obese and non-obese groups, whereas body weight, BMI, fat amount, fat percentage, waist/hip ratio, and baseline level of leptin were significantly higher 
Table 3. Gene expression levels of 19 selected genes, which were differently expressed between obese and non-obese rats, in obese $(n=30)$ and non-obese $(n=20)$ adults

\begin{tabular}{lccc}
\hline Gene name & $\begin{array}{c}\text { Obese }(n=30) \\
(\text { means } \pm \text { SD) }\end{array}$ & $\begin{array}{c}\text { Non-obese }(n=20) \\
(\text { means } \pm \text { SD) }\end{array}$ & $p$ value \\
\hline TFEC & $0.41 \pm 0.36$ & $0.75 \pm 0.47$ & 0.0052 \\
CCL2 & $13.99 \pm 9.98$ & $25.44 \pm 14.00$ & 0.0014 \\
TNFAIP2 & $43.07 \pm 32.67$ & $58.23 \pm 22.33$ & 0.0766 \\
VCAN & $29.51 \pm 16.21$ & $36.24 \pm 17.02$ & 0.1648 \\
ASS1 & $7.83 \pm 4.05$ & $11.41 \pm 4.52$ & 0.0052 \\
HK3 & $2.38 \pm 2.10$ & $2.64 \pm 0.88$ & 0.5554 \\
TNF- $\alpha$ & $13.25 \pm 27.38$ & $3.76 \pm 2.02$ & 0.0686 \\
IL-1 $\beta$ & $10.10 \pm 17.02$ & $1.59 \pm 0.99$ & 0.0105 \\
LPL & $13.69 \pm 15.62$ & $8.12 \pm 5.90$ & 0.0839 \\
IRF1 & $16.34 \pm 13.14$ & $17.68 \pm 6.57$ & 0.6352 \\
STAT & $16.15 \pm 10.60$ & $17.47 \pm 8.79$ & 0.6481 \\
IRG1 & $6.51 \pm 7.33$ & $5.77 \pm 4.25$ & 0.6528 \\
TLR2 & $8.34 \pm 7.68$ & $12.32 \pm 16.93$ & 0.3339 \\
SERPING1 & $12.91 \pm 9.83$ & $17.22 \pm 23.15$ & 0.4399 \\
UBD & $29.79 \pm 20.00$ & $22.18 \pm 12.45$ & 0.1038 \\
CXCL10 & $5.11 \pm 10.91$ & $2.88 \pm 3.06$ & 0.2959 \\
TLR4 & $27.07 \pm 52.19$ & $16.31 \pm 7.54$ & 0.2746 \\
IL-6 & $478.52 \pm 2573.30$ & $7.49 \pm 4.29$ & 0.3244 \\
CXCL11 & $22.03 \pm 42.62$ & $13.92 \pm 12.43$ & 0.3329 \\
\hline
\end{tabular}

These 19 genes were selected for analysis based on previous animal experimental data. TFEC, transcription factor EC; CCL2, chemokine (C-C motif) ligand 2; TNFAIP2, tumor necrosis factor- $\alpha$-induced protein 2; VCAN, versican; ASS1, argininosuccinate synthetase 1; HK3, hexokinase 3; TNF- $\alpha$, tumor necrosis factor- $\alpha$; IL-1 1 , interleukin 1 $\beta$; LPL, lipoprotein lipase; IRF1, interferon regulatory factor 1; STAT, signal transducer and activator of transcription 1; IRG1, immunoresponsive gene 1; TLR2, toll-like receptor 2; SERPING1, serine peptidase inhibitor, clade G, member 1; UBD, ubiquitin D; CXCL10, chemokine (C-X-C motif) ligand 10; TLR4, toll-like receptor 4; IL-6, interleukin 6; CXCL11, chemokine (C-X-C motif) ligand 11. Student's $t$ test was employed.

in the obese group than in the non-obese group (Table 2). Furthermore, baseline adiponectin concentration was significantly lower in the obese group than the non-obese group $(3,953.47$ vs. 6,512.60 ng/mL, $p=0.005$; Table 2).

\section{Gene Expression in PBMCs}

Gene expression levels of a total of 19 previously selected genes were compared between obese and non-obese subjects. IL-1 $\beta$ gene expression in PBMCs was significantly higher in the obese subjects than in the non-obese subjects (10.10 vs. 1.59, $p=0.011$; Table 3 ). Likewise, IL- 6 and TNF- $\alpha$ gene expression in PBMCs was higher in the obese individuals than in the nonobese controls although differences were not statistically significant. In contrast, TFEC, CCL2, and ASS1 gene expression was significantly lower in the obese subjects than in the non-obese controls ( 0.41 vs. $0.75 ; 13.99$ vs. 25.44 ; and 7.83 vs. 11.41 , respectively; Table 3 ). Other gene expression levels were not significantly different between the obese and the non-obese group.

\section{Correlations between Gene Expression in PBMCs and Clinical Obesity Indices}

Nine out of the 19 human PBMC genes had a statistically significant correlation with one or more of the clinical obesity indices (Fig. 1, 2; Table 4). TFEC, CCL2, TNFAIP2, VCAN, ASSI, IRF1, and HK3 showed a negative correlation with BMI, fat amount, fat percentage, waist/hip ratio, and leptin, many of which were statistically significant. In contrast, TNF- $\alpha$ and LPL gene 


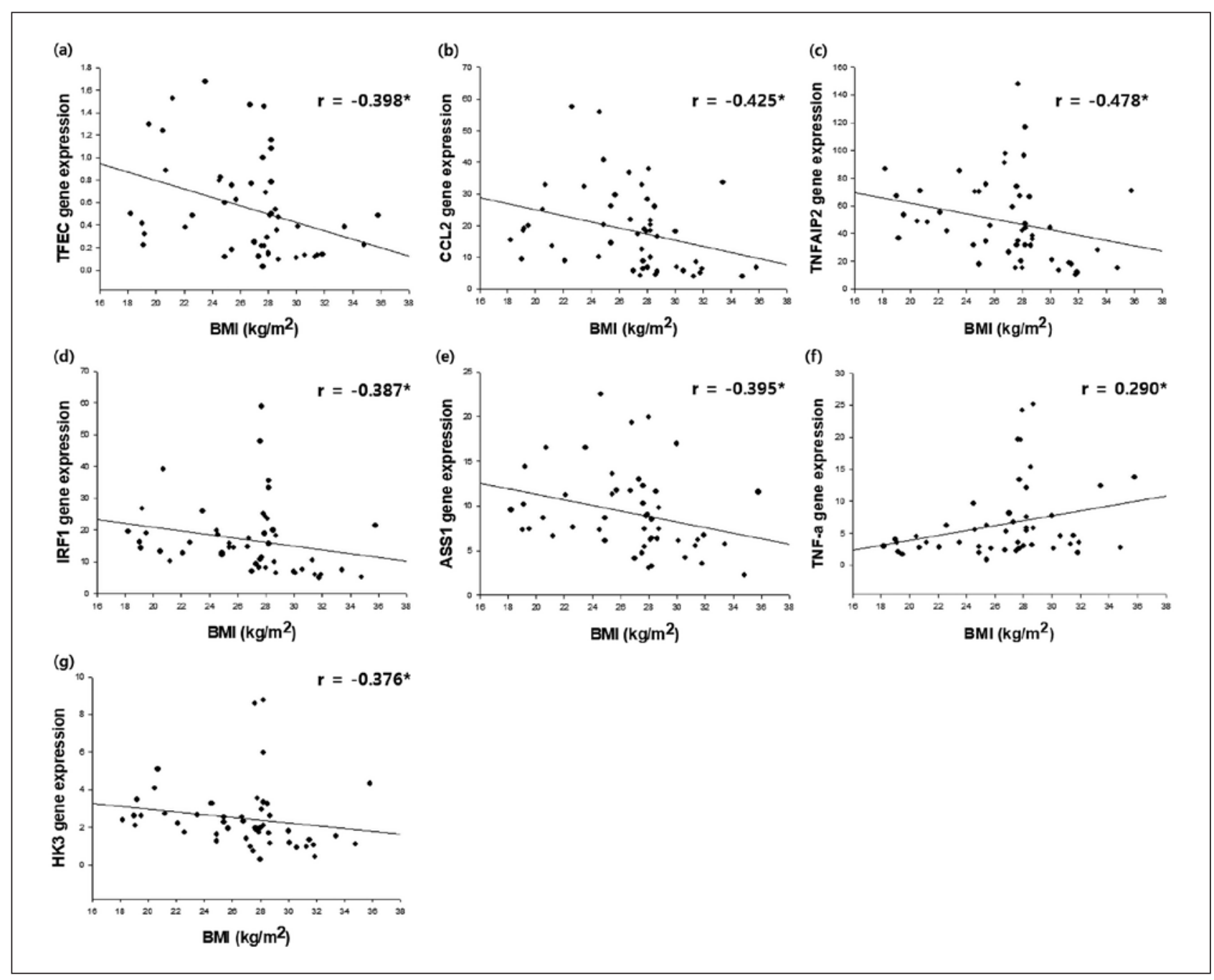

Fig. 1. Correlation of gene expression of TFEC (a), CCL2 (b), TNFAIP2 (c), IRF1 (d), ASS1 (e), TNF-a (f), and HK3 (g) with BMI in adults ( $n=50: 30$ obese and 20 non-obese adults). ${ }^{*} p<0.05$. TFEC, transcription factor EC; CCL2, chemokine (C-C motif) ligand 2; TNFAIP2, tumor necrosis factor- $\alpha$-induced protein 2; IRF1, interferon regulatory factor 1 ; ASS1, argininosuccinate synthetase 1 ; TNF- $\alpha$, tumor necrosis factor- $\alpha$; HK3, hexokinase 3.

expression levels in PBMCs were positively correlated with BMI, fat amount, fat percentage, waist/hip ratio, and leptin concentration, of which the correlations of BMI, waist/hip ratio, and leptin concentration with TNF- $\alpha$ were statistically significant, and the correlation of waist/hip ratio and LPL was statistically significant. On the other hand, adiponectin had a statistically significant negative correlation with TNF- $\alpha(r=-0.307, p=0.032$; Table 4) although it did not show a noticeable correlation with the expression of other genes in PBMCs.

\section{Discussion}

We previously screened a total of 19 candidate murine PBMC genes for obesity in high fat-fed rats [9]. Similar to that study, we used microarray gene expression patterns in the present study to investigate differences in the expression profiles of those 19 genes in human 


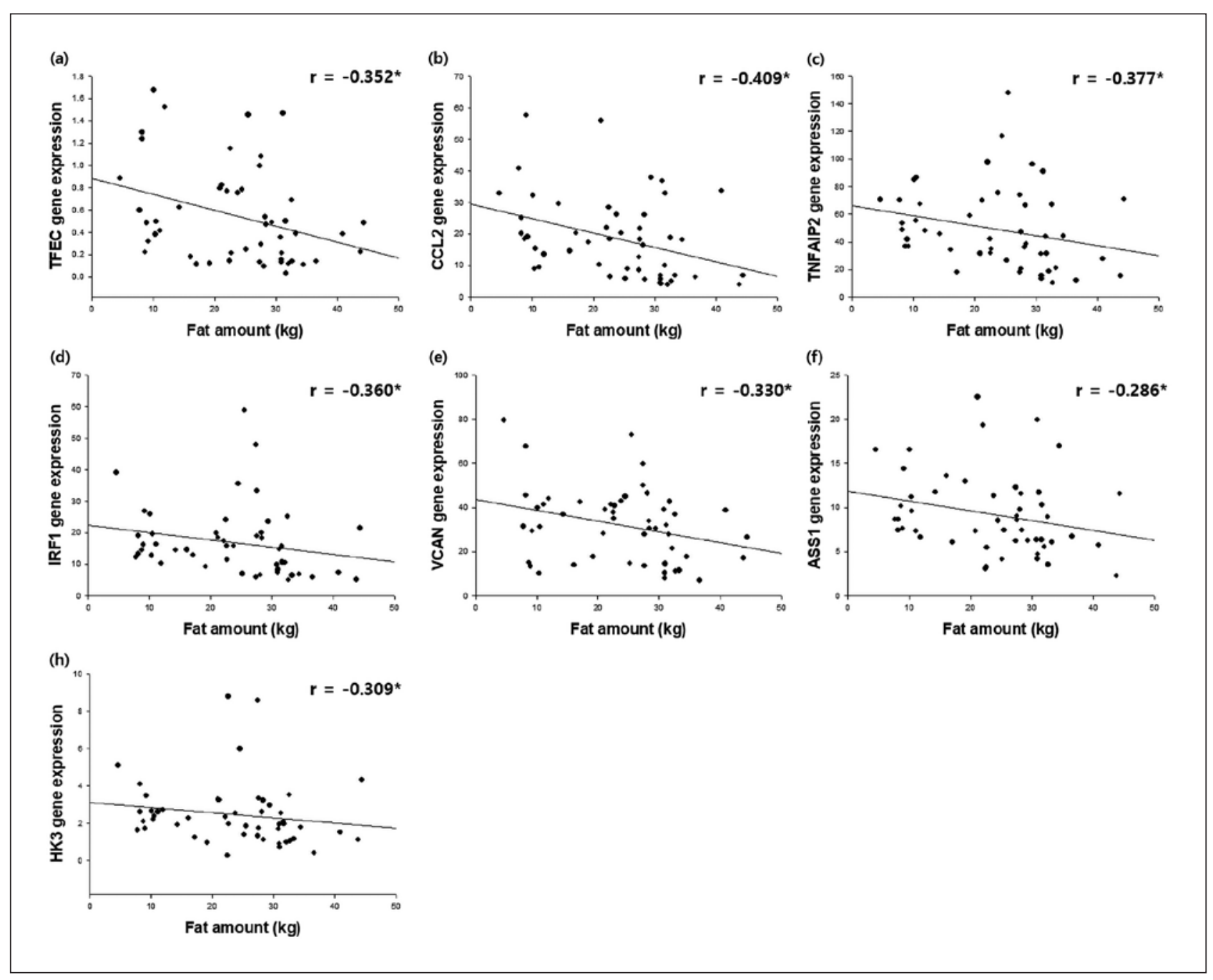

Fig. 2. Correlation of gene expression of TFEC (a), CCL2 (b), TNFAIP2 (c), IRF1 (d), VCAN (e), ASS1 (f), and HK3 (g) with fat amount in adults ( $n=50: 30$ obese and 20 non-obese adults). ${ }^{*} p<0.05$. TFEC, transcription factor EC; CCL2, chemokine (C-C motif) ligand 2; TNFAIP2, tumor necrosis factor- $\alpha$-induced protein 2; IRF1, interferon regulatory factor 1; VCAN, versican; ASS1, argininosuccinate synthetase 1; HK3, hexokinase 3.

PBMCs between obese and non-obese subjects. As a result, 9 of those 19 candidate genes in human PBMCs were significantly correlated with one or more clinical obesity indices such as BMI, fat amount, fat percentage, waist/hip ratio, leptin, and adiponectin in this study.

ASS1, CCL2, and TFEC were not only significantly lower in the obese subjects than in the non-obese controls, they were also negatively correlated with clinical obesity indices, nearly all of which were statistically significant. ASS1 is the enzyme responsible for citrulline metabolism in mammals [27], and argininosuccinate produced via ASS1 is the immediate precursor of arginine, which leads to the production of nitric oxide (NO) in many cells [28]. The availability of NO was diminished in the obese state [29], and low levels of NO increased inflammatory response in vessel lumens [30]. Decreased ASS1 expression in obese subjects reduces NO production, which could contribute to the development of atherosclerosis in this population. Therefore, underexpressed ASS1 can be a potential biomarker for obesity as shown in the present study. 
Jang et al.: PBMCs as a Biomarker for Obesity

Table 4. Spearman's correlation coefficients between 9 genes, which were differently expressed between obese and non-obese adults, and obesity parameters

\begin{tabular}{lllllllllll}
\hline Gene & $\begin{array}{l}\text { BMI, } \\
\mathrm{kg} / \mathrm{m}^{2}\end{array}$ & $\begin{array}{l}\text { Fat, } \\
\mathrm{kg}\end{array}$ & $\begin{array}{l}\text { Fat, } \\
\%\end{array}$ & $\begin{array}{l}\text { Waist/ } \\
\text { hip ratio }\end{array}$ & $\begin{array}{l}\text { Leptin, } \\
\mathrm{pg} / \mathrm{mL}\end{array}$ & $\begin{array}{l}\text { Adiponectin, } \\
\mathrm{ng} / \mathrm{mL}\end{array}$ & $\begin{array}{l}\text { Insulin, } \\
\mathrm{mU} / \mathrm{L}\end{array}$ & $\begin{array}{l}\text { Total C, } \\
\mathrm{mg} / \mathrm{dL}\end{array}$ & $\begin{array}{l}\text { Triglycer- } \\
\text { ide, mg/dL }\end{array}$ & $\begin{array}{l}\text { FFA, } \\
\mu \mathrm{Eq} / \mathrm{L}\end{array}$ \\
\hline TFEC & $-0.398^{*}$ & $-0.352^{*}$ & $-0.315^{*}$ & $-0.337^{*}$ & $-0.35^{*}$ & -0.038 & -0.063 & -0.097 & 0.049 & 0.113 \\
CCL2 & $-0.425^{*}$ & $-0.409^{*}$ & $-0.338^{*}$ & $-0.352^{*}$ & $-0.358^{*}$ & 0.09 & -0.198 & -0.064 & 0.093 & 0.137 \\
TNFAIP2 & $-0.478^{*}$ & $-0.377^{*}$ & $-0.316^{*}$ & $-0.335^{*}$ & -0.28 & 0.069 & 0.018 & -0.167 & -0.117 & -0.065 \\
IRF1 & $-0.387^{*}$ & $-0.360^{*}$ & $-0.286^{*}$ & -0.238 & $-0.286^{*}$ & -0.089 & -0.076 & -0.243 & -0.066 & 0.087 \\
VCAN & -0.263 & $-0.330^{*}$ & $-0.290^{*}$ & $-0.290^{*}$ & -0.165 & -0.137 & 0.223 & -0.005 & 0.088 & 0.11 \\
ASSI & $-0.395^{*}$ & $-0.286^{*}$ & -0.211 & -0.245 & -0.243 & 0.07 & -0.23 & -0.191 & -0.265 & -0.085 \\
TNF- $\alpha$ & $0.290^{*}$ & 0.235 & 0.250 & $0.438^{*}$ & $0.28^{*}$ & $-0.307^{*}$ & -0.054 & 0.241 & 0.26 & 0.107 \\
HK3 & $-0.376^{*}$ & $-0.309^{*}$ & -0.214 & -0.233 & -0.247 & 0.077 & -0.018 & -0.145 & -0.036 & 0.106 \\
LPL & 0.116 & 0.159 & 0.168 & $0.339^{*}$ & 0.185 & -0.236 & 0.014 & 0.086 & -0.098 & -0.131 \\
\hline
\end{tabular}

C, cholesterol; FFA, free fatty acids; TFEC, transcription factor EC; CCL2, chemokine (C-C motif) ligand 2; TNFAIP2, tumor necrosis factor- $\alpha$-induced protein 2; IRF1, interferon regulatory factor 1; VCAN, versican; ASS1, argininosuccinate synthetase 1; TNF- $\alpha$, tumor necrosis factor- $\alpha$; HK3, hexokinase 3 ; LPL, lipoprotein lipase. ${ }^{*} p<0.05$.

CCL2 and TFEC gene expression is more complicated, and inconsistent findings have been reported. The CCL2 (also known as MCP-1) gene is a major chemokine that regulates migration and infiltration of monocytes and macrophages. CCL2 expression in human adipose tissue was positively correlated with the degree of obesity [31], and the plasma level of CCL2 was increased in obese adults compared with normal weight subjects [25, 32]. Likewise, TFEC is a known mediator of proinflammatory G-CSF (granulocyte colony-stimulating factor) gene expression, and TFEC was associated with insulin resistance in human adipocytes [33]. However, other studies showed conflicting results in agreement with ours. For example, expression of proinflammatory genes including IL-6, IL-1 $\beta$, IL-1Ra, and CCL2 in PBMCs was reduced in the obese group [34,35]. Therefore, reduced expression of the CCL2 and TFEC genes in PBMCs in our results may represent a compensatory response to maintain homeostasis. Namely, proinflammatory gene expression in PBMCs could have been suppressed to maintain the body homeostasis in the low-grade inflammatory state caused by obesity.

The same homeostasis hypothesis may explain why the expression levels of the VCAN and TNFAIP2 genes in PBMCs were reduced in obese subjects in our results. VCAN plays an important role in lipid accumulation, inflammation, and thrombosis [22]. Furthermore, TNFAIP2 significantly increased inflammatory response with TNF- $\alpha$ [36]. Therefore, VCAN and TNFAIP2 expression is likely to be increased in obese individuals. However, the opposite finding was observed in the present study, which could again be explained by the homeostasis hypothesis.

The differences in TNF- $\alpha$ and LPL expression in PBMCs between the obese and the nonobese subjects was similar to those seen in previous studies. For example, the expression of TNF- $\alpha$ in PBMCs increased with increasing obesity. The mRNA level of TNF- $\alpha$ was significantly increased as leptin concentration was increased [37]. Furthermore, overexpression of TNF- $\alpha$ induced by leptin is more sensitive in obese subjects than in normal-weight individuals. On the other hand, clinical obesity indices were positively correlated with LPL expression in the liver and muscle tissue [38]. This suggests that LPL expression was increased in endothelial cells located in the liver and muscle tissue, and triglycerides migrated from lipoprotein to the tissue in obese patients [38].

The expression of HK3 and IRF1 in PBMCs tended to decrease in the obese subjects compared with the non-obese controls although they failed to show statistical significance. HK3 expression was inhibited by physiological concentration of glucose [39]. Therefore,

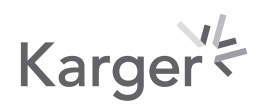


increased blood glucose concentration in obese patients could inhibit the action of HK3. Similarly, IRF1 has been reported to regulate adipogenesis, and reduced IRF1 could elevate lipid accumulation [40], which is likely to happen in obese subjects as reflected in our results.

The present study had several limitations. First, the number of obese subjects was small. Second, the mean BMI of obese subjects in this study was relatively modest, i.e., 29.36 $\mathrm{kg} / \mathrm{m}^{2}$ (range: $27.0-35.8 \mathrm{~kg} / \mathrm{m}^{2}$ ). Therefore, our results may differ from the findings in subjects with extreme or severe obesity. In this study, we used a BMI of $27 \mathrm{~kg} / \mathrm{m}^{2}$ as the cutoff that divided subjects into obese and non-obese subjects, consistent with the WHO classification in Asians. Thus, the obesity criteria adopted in the present study were sufficient to show the difference in the gene expression between the obese and the non-obese subjects. Third, we did not test if the identified gene expression could change in response to obesity treatment. Further studies with a larger number of obese subjects are warranted to confirm our findings.

\section{Conclusion}

We identified 9 genes out of the 19 candidate genes in human PBMCs that significantly correlated with one or more clinical obesity indices: ASS1, CCL2, TFEC, VCAN, TNFAIP2, TNF- $\alpha$, LPL, HK3, and IRF1. These genes have a mechanistic basis for the development or progression of obesity and its metabolic derangements, which may help to determine possible underlying mechanisms for obesity.

\section{Acknowledgment}

This research was supported by the BK21 Plus Program of the National Research Foundation of Korea (NRF) (10Z20130000017).

\section{Statement of Ethics}

The study protocol was reviewed and approved by the Institutional Review Board of the Seoul National University Hospital (IRB No. H-1411-097-628). All the subjects provided written informed consent after a detailed explanation of the study prior to any study procedure. This study was conducted in full accordance with the principles of the Declaration of Helsinki and Good Clinical Practice as codified in the ICH guidelines (ICH E6) and other regulations.

\section{Disclosure Statement}

The authors have no conflicts of interest to declare.

\section{Funding Sources}

None.

\section{Karger'}




\begin{tabular}{|c|c|}
\hline Obes Facts 2020;13:375-385 & \\
\hline DOI: 10.1159/000507817 & $\begin{array}{l}\text { (c) } 2020 \text { The Author(s). Published by S. Karger AG, Basel } \\
\text { www.karger.com/ofa }\end{array}$ \\
\hline
\end{tabular}

Jang et al.: PBMCs as a Biomarker for Obesity

\section{References}

1 Ng M, Fleming T, Robinson M, Thomson B, Graetz N, Margono C, et al. Global, regional, and national prevalence of overweight and obesity in children and adults during 1980-2013: a systematic analysis for the Global Burden of Disease Study 2013. Lancet. 2014 Aug;384(9945):766-81.

2 WHO Expert Consultation. Appropriate body-mass index for Asian populations and its implications for policy and intervention strategies. Lancet. 2004 Jan;363(9403):157-63.

3 Sahoo K, Sahoo B, Choudhury AK, Sofi NY, Kumar R, Bhadoria AS. Childhood obesity: causes and consequences. J Family Med Prim Care. 2015 Apr-Jun;4(2):187-92.

4 Biomarkers Definitions Working Group. Biomarkers and surrogate endpoints: preferred definitions and conceptual framework. Clin Pharmacol Ther. 2001 Mar;69(3):89-95.

5 Erre GL, Piga M, Carru C, Angius A, Carcangiu L, Piras M, et al. Global microRNA profiling of peripheral blood mononuclear cells in patients with Behçet's disease. Clin Exp Rheumatol. 2015 Nov-Dec;33(6 Suppl 94):S72-9.

6 Burczynski ME, Peterson RL, Twine NC, Zuberek KA, Brodeur BJ, Casciotti L, et al. Molecular classification of Crohn's disease and ulcerative colitis patients using transcriptional profiles in peripheral blood mononuclear cells. J Mol Diagn. 2006 Feb;8(1):51-61.

7 Končarević S, Lößner C, Kuhn K, Prinz T, Pike I, Zucht HD. In-depth profiling of the peripheral blood mononuclear cells proteome for clinical blood proteomics. Int J Proteomics. 2014;2014:129259.

8 Oliver P, Reynés B, Caimari A, Palou A. Peripheral blood mononuclear cells: a potential source of homeostatic imbalance markers associated with obesity development. Pflugers Arch. 2013 Apr;465(4):459-68.

9 Park T. Method for searching a drug for preventing and treating obesity using gene index in a blood sample. Korea patent 101101756. 2010.

10 Herder C, Hauner H, Kempf K, Kolb H, Skurk T. Constitutive and regulated expression and secretion of interferon-gamma-inducible protein 10 (IP-10/CXCL10) in human adipocytes. Int J Obes. 2007 Mar;31(3):403-10.

11 Liu LF, Shen WJ, Ueno M, Patel S, Azhar S, Kraemer FB. Age-related modulation of the effects of obesity on gene expression profiles of mouse bone marrow and epididymal adipocytes. PLoS One. 2013 Aug;8(8):e72367.

12 Michelucci A, Cordes T, Ghelfi J, Pailot A, Reiling N, Goldmann 0, et al. Immune-responsive gene 1 protein links metabolism to immunity by catalyzing itaconic acid production. Proc Natl Acad Sci USA. 2013 May;110(19): 7820-5.

13 Coerver KA, Gray SM, Barnes JE, Armstrong DL, McCabe ER. Developmental expression of hexokinase 1 and 3 in rats. Histochem Cell Biol. 1998 Jan;109(1):75-86.

14 Wolfl M, Kuball J, Ho WY, Nguyen H, Manley TJ, Bleakley M, et al. Activation-induced expression of CD137 permits detection, isolation, and expansion of the full repertoire of CD8+ T cells responding to antigen without requiring knowledge of epitope specificities. Blood. 2007 Jul;110(1):201-10.

15 Nussler AK, Billiar TR, Liu ZZ, Morris SM Jr. Coinduction of nitric oxide synthase and argininosuccinate synthetase in a murine macrophage cell line. Implications for regulation of nitric oxide production. J Biol Chem. 1994 Jan;269(2):1257-61.

16 Choi JW, Wang X, Joo JI, Kim DH, Oh TS, Choi DK, et al. Plasma proteome analysis in diet-induced obesity-prone and obesity-resistant rats. Proteomics. 2010 Dec;10(24):4386-400.

17 Archacki SR, Angheloiu G, Tian XL, Tan FL, DiPaola N, Shen GQ, et al. Identification of new genes differentially expressed in coronary artery disease by expression profiling. Physiol Genomics. 2003 Sep;15(1):65-74.

18 Rehli M, Sulzbacher S, Pape S, Ravasi T, Wells CA, Heinz S, et al. Transcription factor Tfec contributes to the IL-4-inducible expression of a small group of genes in mouse macrophages including the granulocyte colonystimulating factor receptor. J Immunol. 2005 Jun;174(11):7111-22.

19 Ballak DB, Stienstra R, Tack CJ, Dinarello CA, van Diepen JA. IL-1 family members in the pathogenesis and treatment of metabolic disease: focus on adipose tissue inflammation and insulin resistance. Cytokine. 2015 Oct; 75(2):280-90.

20 Salem S, Gao C, Li A, Wang H, Nguyen-Yamamoto L, Goltzman D, et al. A novel role for interferon regulatory factor 1 (IRF1) in regulation of bone metabolism. J Cell Mol Med. 2014 Aug;18(8):1588-98.

21 Gurzov EN, Stanley WJ, Pappas EG, Thomas HE, Gough DJ. The JAK/STAT pathway in obesity and diabetes. FEBS J. 2016 Aug;283(16):3002-15.

22 Wight TN, Merrilees MJ. Proteoglycans in atherosclerosis and restenosis: key roles for versican. Circ Res. 2004 May;94(9):1158-67.

23 Serra MC, Ryan AS, Goldberg AP. Reduced LPL and subcutaneous lipid storage capacity are associated with metabolic syndrome in postmenopausal women with obesity. Obes Sci Pract. 2017 Mar;3(1):106-14.

24 Jialal I, Kaur H, Devaraj S. Toll-like receptor status in obesity and metabolic syndrome: a translational perspective. J Clin Endocrinol Metab. 2014 Jan;99(1):39-48.

25 Panee J. Monocyte Chemoattractant Protein 1 (MCP-1) in obesity and diabetes. Cytokine. 2012 Oct;60(1): $1-12$.

26 Mohammadi M, Gozashti MH, Aghadavood M, Mehdizadeh MR, Hayatbakhsh MM. Clinical Significance of Serum IL-6 and TNF- $\alpha$ Levels in Patients with Metabolic Syndrome. Rep Biochem Mol Biol. 2017 Oct;6(1): 74-9.

27 Morris SM Jr. Arginine metabolism: boundaries of our knowledge. J Nutr. 2007 Jun;137(6 Suppl 2):1602S-9S.

28 Husson A, Brasse-Lagnel C, Fairand A, Renouf S, Lavoinne A. Argininosuccinate synthetase from the urea cycle to the citrulline-NO cycle. Eur J Biochem. 2003 May;270(9):1887-99. 
29 Sansbury BE, Hill BG. Regulation of obesity and insulin resistance by nitric oxide. Free Radic Biol Med. 2014 Aug;73:383-99.

30 Goodwin BL, Pendleton LC, Levy MM, Solomonson LP, Eichler DC. Tumor necrosis factor-alpha reduces argininosuccinate synthase expression and nitric oxide production in aortic endothelial cells. Am J Physiol Heart Circ Physiol. 2007 Aug;293(2):H1115-21.

31 Christiansen T, Richelsen B, Bruun JM. Monocyte chemoattractant protein-1 is produced in isolated adipocytes, associated with adiposity and reduced after weight loss in morbid obese subjects. Int J Obes. 2005 Jan; 29(1):146-50.

32 Catalán V, Gómez-Ambrosi J, Ramirez B, Rotellar F, Pastor C, Silva C, et al. Proinflammatory cytokines in obesity: impact of type 2 diabetes mellitus and gastric bypass. Obes Surg. 2007 Nov;17(11):1464-74.

33 Ordelheide AM, Gommer N, Böhm A, Hermann C, Thielker I, Machicao F, et al. Granulocyte colony-stimulating factor (G-CSF): A saturated fatty acid-induced myokine with insulin-desensitizing properties in humans. Mol Metab. 2016 Feb;5(4):305-16.

34 O'Rourke RW, Kay T, Lyle EA, Traxler SA, Deveney CW, Jobe BA, et al. Alterations in peripheral blood lymphocyte cytokine expression in obesity. Clin Exp Immunol. 2006 Oct;146(1):39-46.

35 Fontana L, Eagon JC, Colonna M, Klein S. Impaired mononuclear cell immune function in extreme obesity is corrected by weight loss. Rejuvenation Res. 2007 Mar;10(1):41-6.

36 Brohawn DG, O’Brien LC, Bennett JP Jr. RNAseq Analyses Identify Tumor Necrosis Factor-Mediated Inflammation as a Major Abnormality in ALS Spinal Cord. PLoS One. 2016 Aug;11(8):e0160520.

37 Raskin Erusan R, Nalini D, Manohar G, Malathi R. Correlation between Obesity and Inflammation in Cardiovascular Diseases-Evaluation of Leptin and Inflammatory Cytokines. Open J Endocr Metab Dis. 2012;2(02): 7-15.

38 Kim JK, Fillmore JJ, Chen Y, Yu C, Moore IK, Pypaert M, et al. Tissue-specific overexpression of lipoprotein lipase causes tissue-specific insulin resistance. Proc Natl Acad Sci USA. 2001 Jun;98(13):7522-7.

39 Patra KC, Wang Q, Bhaskar PT, Miller L, Wang Z, Wheaton W, et al. Hexokinase 2 is required for tumor initiation and maintenance and its systemic deletion is therapeutic in mouse models of cancer. Cancer Cell. 2013 Aug; 24(2):213-28.

40 Eguchi J, Yan QW, Schones DE, Kamal M, Hsu CH, Zhang MQ, et al. Interferon regulatory factors are transcriptional regulators of adipogenesis. Cell Metab. 2008 Jan;7(1):86-94. 